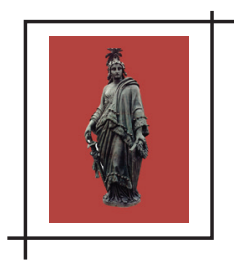

\title{
VONTADE E LIBERDADE EM TOMÁS DE AQUINO'
}

\author{
Javier García-Valiño Abós²
}

Resumo: Tomás de Aquino, em italiano Tommaso d'Aquino (1225-1274), é um autor cristão do periodo medieval que, com uma extraordinária audácia intelectual e amplitude de visão, dialoga metódica e criticamente com Aristóteles e com toda a tradição filosófica e teológica, elaborando uma sintese equilibrada e original - tão bela como difícil - sobre os grandes problemas da filosofia. 0 presente artigo focaliza a atenção na vontade e na liberdade. Aqui se trata da vontade entendida como uma potência ou faculdade (superior) da alma humana: o apetite racional, o apetite do bem e da felicidade. Tomás de Aquino é receptor e intérprete de um rico acervo de reflexões e teses sobre a vontade. Por um lado, Aristóteles oferece a Tomás de Aquino o marco filosófico e o aparato conceitual básico, matizado e enriquecido pelos estoicos e por Alexandre de Afrodísia. E, por outro, o horizonte do pensamento cristão, bem articulado na patrística com a filosofia grega, aportando uma perspectiva nova e mais específica sobre a vontade e, ainda, oferecendo as chaves para compreender a relevância antropológica e ética da vontade, e sua peculiar relação com o entendimento e as demais potências da alma humana. Assim, o tema da vontade em Tomás de Aquino, que primazia a vontade sobre o intelecto, adquire seus elementos fundamentais em Aristóteles, Agostinho, Máximo e Damasceno.

Palavras-chave: Liberdade. Vontade. Felicidade. Tomás de Aquino. Livre-arbitrio.

\section{INTRODUÇÃO: TOMÁS DE AQUINO EM DIÁLOGO COM A TRADIÇÃO FILOSÓFICA}

Tomás de Aquino, João Duns Escoto e Guilherme de Ockham, grandes mestres da filosofia medieval, são três marcos decisivos na evolução e transformação do pensamento cristão, desde a plenitude da escolástica no Aquinate até a dissolução ou cancelamento da filosofia medieval em Ockham. Nessa senda, Duns Escoto constitui, certamente, um "ponto de inflexão". Depois da sintese tomista, Escoto, com a sua nova interpretação de Aristóteles, vai sentar as bases do voluntarismo filosófico. Contudo, o sentido e o alcance da posição de Escoto como ponto de inflexão para o voluntarismo não podem ser entendidos isoladamente, mas sim em relação com a tradição filosófica e, em particular, com o Aquinate.

1 - Tradução do espanhol: Adriana Ribeiro (Universidad de Concepción).

2 - Doutor em Filosofia pela Universidad de Málaga, Espanha. Professor de Filosofia na Universidad de Murcia, Espanha. E-mail: jgarciaval@gmail.com 
Tomás de Aquino é um autor cristão que, com uma extraordinária audácia intelectual e amplitude de visão, dialoga metódica e criticamente com Aristóteles e com toda a tradição filosófica e teológica, e elabora uma síntese equilibrada e original - tão bela como difícil sobre os grandes problemas da filosofia. Entre eles, por agora, vamos focalizar a atenção na vontade e na liberdade. Aqui se trata da vontade entendida como uma potência ou faculdade (superior) da alma humana: o apetite racional, o apetite do bem e da felicidade.

Tomás de Aquino é receptor e intérprete de um rico acervo de reflexões e teses sobre a vontade. 0 valor e a singularidade do seu aporte - seja nesse tema como em outros - estão em ter logrado uma integração sistemática e uma síntese original da doutrina patrística (ocidental e oriental) com a psicologia, a antropologia e a teoria da ação de Aristóteles, unidas a certos conceitos da tradição estoica. Por um lado, Aristóteles oferece o marco filosófico e o aparato conceitual básico, matizado e enriquecido pelos estoicos e por Alexandre de Afrodísia. Por outro, o horizonte do pensamento cristão, bem articulado na patrística com a filosofia grega, aportando uma perspectiva nova e mais específica sobre a vontade e, ainda, oferecendo as chaves para compreender a relevância antropológica e ética da vontade, e sua peculiar relação com o entendimento e as demais potências da alma humana.

Com relação à doutrina dos padres da Igreja, são duas as suas fontes principais: de um lado, na patrística latina-ocidental, a reflexão de Agostinho de Hipona (séculos IV-V); de outro, na patrística grega-oriental, a doutrina de Máximo, o Confessor, e João Damasceno (séculos VII-VIII), recebida pelos mestres escolásticos dos séculos XII e XIII. De fato, os dois padres orientais marcam com precisão as linhas gerais da sintese tomista. Assim, os elementos fundamentais dessa síntese procedem de Aristóteles, Agostinho, Máximo e Damasceno.

\section{INTELECTUALISMO E VOLUNTARISMO NA FILOSOFIA CRISTIANA}

A interpretação tradicional da antropologia e da ética de Tomás tem uma clara inclinação "intelectualista", ainda que a tendência esteja mudando nos últimos quarenta anos. Tomás de Aquino é intelectualista? Essa questão faz referência direta ao problema das relações entre inteligência e vontade, que chegou a ser uma das questões cruciais do pensamento medieval. Cabe considerar como intelectualista toda concepção filosófica que afirme a primazia do intelecto sobre a vontade; e como voluntarista a concepção inversa: a que afirme a primazia da vontade sobre o intelecto.

Com razão, L. Polo (1998) observa que a vontade encontra, à luz da Revelação judaico-cristã, um lugar relevante na compreensão de Deus e do ser humano como seres pessoais. ${ }^{3}$

3 - Como se sabe, o conceito de pessoa, como conceito metafísico, ainda que esboçado ou prefigurado já pelos estoicos, é de origem cristã: elabora e desenvolve-se num contexto teológico, durante a constituição do dogma da Trindade divina e a controvérsia cristológica. Nesse processo, foi essencial a distinção entre pessoa e natureza. 
Mas, uma vez que a vontade tem adquirido essa relevância, a tradição patristica e medieval caracteriza-se, em geral, por afirmar certa prioridade ou primazia do entendimento a respeito da vontade. Essa prioridade se deve, em grande medida, à decisiva influência da filosofia grega no pensamento cristão. Essa tradição é acolhida e completada por Tomás de Aquino. Mas Tomás, como herdeiro e intérprete dessa tradição, sem deixar de ser "intelectualista" em um sentido que se tem que precisar e matizar muito bem e que não está livre de problemas -, corrige o familiarizado intelectualismo de Platão e o intelectualismo moderado de Aristóteles e consegue um notável equilibrio entre ambas faculdades.

Esse difícil equilibrio se rompe e essa longa tradição se interrompe com certos autores medievais tardios, os quais, em defesa de que a vontade é superior à inteligência, atendendo à omnipotência divina, vão sustentar as bases da interpretação moderna da vontade. Assim, é certo que "o projeto de pôr a vontade acima do entendimento começou a ser formulado por São Boaventura e ganhou força em João Duns Scotus e Guilherme de Ockham, de onde veio para os filósofos modernos" (POLO, 1998, p. 8, tradução nossa) ${ }^{4}$. Estamos diante de três pensadores da baixa Idade Média, franciscanos ${ }^{5}$ que constituem (principalmente os dois últimos) referências importantes na história da noção de vontade, posto que introduzem uma profunda mudança de orientação que bem poderíamos denominar "giro voluntarista" do pensamento cristão medieval.

\section{NATUREZA E LIBERDADE: A ARTICULAÇÃO DE VOLUNTAS UT NATURA E VOLUNTAS UT RATIO. RELAÇÃO ENTRE INTELIGÊNCIA E VONTADE}

Ao tratar da vontade, Tomás distingue com clareza entre a potência da alma, os atos ou operações e os hábitos da vontade. Considerando a vontade como ato, isto é, a volição ou o querer humano, distingue duas "facetas" nele: voluntas ut natura e voluntas ut ratio (vontade como natureza e vontade como razão).

A noção tomista de voluntas ut natura recolhe o sentido da $\theta$ é $\lambda \eta \sigma s$ de Damasceno:

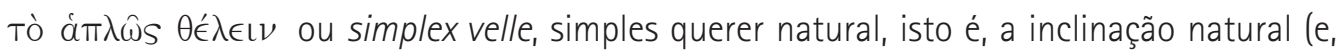
por isso, "necessária") da vontade que Tomás expressa como "o bem em geral" (bonum in communi) e a felicidade. Portanto, se trata da volição natural do bem e do fim último. É o momento natural do querer humano.

\footnotetext{
4 - "el proyecto de poner la voluntad por encima del entendimiento comienza a formularse en San Buenaventura, y adquiere fuerza en Juan Duns Escoto y en Guillermo de Ockham, de donde pasa a los filósofos modernos".

5 - Como alguns autores destacam, não é por acaso que os três sejam franciscanos. Seguramente, esta nova interpretação da vontade (e da relação entre o intelecto e a vontade) e esta nova corrente "voluntarista" estão em relação com algum aspecto ou caracteristica importante do carisma ou a espiritualidade franciscana; e é óbvio que, também, tem que ver com certo "apego" dos autores franciscanos à tradição agostiniana, ainda que alguns deles (singularmente, J. Duns Escoto) ousaram dialogar seriamente com Aristóteles.
} 
A noção tomista de voluntas ut ratio expressa a vontade deliberativa e eletiva, isto é, a

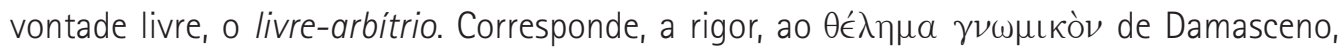
ainda que a expressão grega inclua um matiz semântico importante: um elemento afetivo (uma disposição afetiva) que não acolhe a expressão tomista voluntas ut ratio nem outras expressões latinas mais ou menos equivalentes de outros mestres escolásticos.

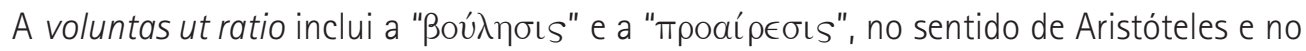

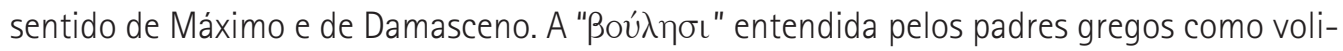

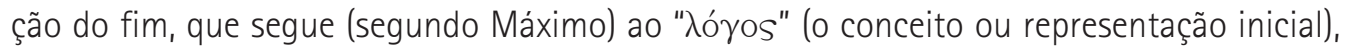
equivale à intentio de Tomás, que segue à apprehensio. Na teoria sobre o processo da ação

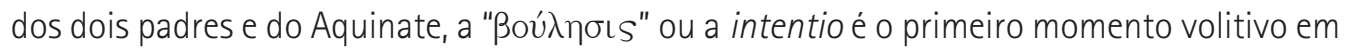
dito processo.

Certamente, o alcance da voluntas ut ratio em Tomás é também mais ampla que a

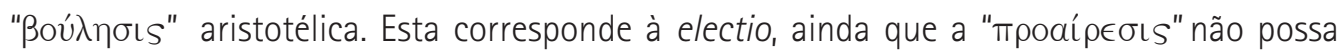
reduzir-se à electio mediorum (escolha dos meios). 0 exercício da voluntas ut ratio compreende todos os atos volitivos que, articulados com os atos cognitivos aos que seguem, constituem a ação humana: a intentio (intenção), o consensus (consentimento), a electio (escolha) e o usus (uso).

Ambas facetas do querer humano - ut natura e ut ratio - não são contraditórias entre si, e se dão sempre inseparavelmente (unidas). 0 seu significado antropológico e metafísico é muito importante porque os termos voluntas ut natura e voluntas ut ratio expressam as duas dimensões constitutivas da vontade humana: de um lado, a natural ou nativa; de outro, a racional, isto é, o livre-arbitrio, a liberdade. Assim, natureza e liberdade "convivem" no querer humano: a inclinação "necessária" da vontade para o bem e o fim último se articula em harmonia com o exercício da liberdade pessoal. A determinação da vontade ut natura para um fim último (natura ad unum/numa só direção) se concilia com a indeterminação (e autodeterminação) da voluntas ut ratio (deliberativa e eletiva) com relação aos bens particulares (ratio ad opposita seu diversa), "natura ad unum, ratio ad opposita seu diversa" (ou seja: "O racional se dirige para uma única direção, enquanto o irracional se dirige para os contrários"). Tomás de Aquino recebe da tradição um problema complexo de grande relevância antropológica: a relação entre intelecto e vontade. A esse problema presta uma atenção especial em muitos lugares de sua obra.

Os textos expressam de muitos modos que as duas potências, sendo distintas e irredutíveis entre si, não podem se separar: estão estreitamente entrelaçadas, harmonicamente articuladas; e a operação conjunta de ambas constitui a unidade cognitivo-volitiva da ação humana. Estão articuladas e são permeáveis entre si de tal modo que bem pode se dizer que não há atos "puros" da vontade. Com efeito, o intelecto e a vontade são permeáveis entre si. Por um lado, o intelecto pode ter por objeto a vontade: conhecer sua Natureza e seus atos; por outro, a vontade pode versar sobre o intelecto: quer entender e mover o intelecto a rea- 
lizar os seus atos. A sindérese é aqui, também, uma noção-chave: ela, como instância cognoscitiva superior e comum, torna possivel essa permeabilidade mútua entre as duas potências espirituais da alma.

Diante dessa concepção tomista das relações entre intelecto e vontade, com Duns Escoto começa o processo de "desvinculação" da vontade, que será consumado na modernidade e encontrará formulações radicais no século XIX, principalmente em Schopenhauer e Nietzsche.

A tese fundamental de Tomás é que o conhecer sempre precede de algum modo o querer. Assim é que, em muitos textos afirma uma precedência ou prioridade do conhecer em relação ao apetecer, e da intelecção em relação à volição, posto que não se pode apetecer, querer ou amar o que não se conhece de algum modo. A vontade, em sua origem e em seu exercício, pressupõe o intelecto. A vontade segue sempre, de algum modo, em seu exercício, o entendimento, inclinando-se livremente para os bens que este apresenta ou propõe; e, também, depende dele, num certo sentido.

No entanto, como a vontade é uma potência motriz, move o intelecto a realizar os próprios atos: entendemos porque queremos entender. Por outro lado, há uma volição natural do bem em geral e do fim último: o simplex velle, isto é, a voluntas ut natura, que precede a muitos atos de conhecimento. Assim, se consideramos o trabalho humano, "[...] no mover ou no agir, a vontade é anterior (precedente), uma vez que toda ação ou movimento é baseado na intenção do bem" (TOMÁS DE AQUINO, De Ver., q. 14, a. 5. ad 5, tradução nossa)6.

Essas afirmações não são contraditórias com a tese fundamental. Cabe falar de uma prioridade ou precedência reciproca entre o entendimento e a vontade, ainda que Tomás sempre destaque que a prioridade stricto sensu é do entendimento:
[...] não é necessário estabelecer um processo ao infinito, mas parar no entendimento como no primeiro. Para todo movimento da vontade é necessário que Ihe preceda um conheci- mento. Mas não o contrário: nem todo conhecimento vem antes de um movimento volun- tário (TOMÁS DE AQUINO, S. Th., I, q. 82. a. 4, ad 3, tradução nossa).?

Na alma humana, a potência (superior) menos ativa ou mais potencial depende da mais ativa ou menos potencial, e não se explica senão a partir desta. Portanto, a hierarquia entre as duas potências, contemplada como relação de dependência, se deve a que a inteligência é mais ativa e a vontade é menos ativa ou passivo-ativa.

6 - "(...) en el mover o en el actuar, la voluntad es anterior (precedente), ya que toda acción o movimiento es a partir de la intención del bien".

7 - "(...) no es necesario establecer un proceso al infinito, sino detenerse en el entendimiento como en lo primero. Pues a todo movimiento de la voluntad es necesario que le preceda un conocimiento. Mas no a la inversa: no a todo conocimiento precede una moción voluntaria". 
A prioridade do intelecto e do conhecer, tal como é matizada pelo mesmo Tomás, não é, pois, absoluta, e também não diminui de modo algum a alta dignidade que a vontade tem na antropologia do Aquinate. Do estudo de seus textos pode-se inferir que essa dignidade se baseia, principalmente, nas razões que seguem. Em primeiro lugar, ela é a potência motriz de todas as demais potências da alma: a que move cada uma aos atos próprios.

Em segundo lugar, a teoria da ação de Tomás mostra que os atos cognitivos não podem, por si, mover o agente humano: são os atos da vontade, inseparáveis daqueles, os que o impulsam a obrar. Nesse ponto, Tomás se mantém fiel à tese aristotélica: a razão sem desejo não pode mover o agente.

Em terceiro lugar, como a vontade é livre (mais livre do que o entendimento), a dignidade da liberdade enaltece o valor da vontade, ainda que se possa afirmar que o livre-arbítrio da vontade radica na pessoa mesma.

Em quarto lugar, a dignidade da vontade se funda na primazia do amor (pessoal): a dilectio e a caritas. A pessoa humana se aperfeiçoa mais no amor, como união afetiva e efetiva com o amado, do que na mera inteleção.

Assim, não podemos concluir que Tomás seja "intelectualista", como se pode inferir da maioria dos comentários e estudos tradicionais, ainda que nos últimos quarenta anos a tendência hermenêutica tenha mudado; mas tão pouco "voluntarista", como são, em diversos graus e modos, os pensadores da escola franciscana a partir de J. Duns Escoto. 0 exame dos textos do Aquinate nos obriga a corrigir uma certa interpretação que, ao destacar a primazia do intelecto, não soube apreciar a importância da vontade na Natureza e existência humana. Essa interpretação é a que tem predominado na escolástica e na neoescolástica. Num certo sentido, a vontade é "mais excelsa" que a inteligência, porque é mais excelso querer e amar bem algo (ou alguém) e perseguir ou procurar ativamente o bem da pessoa amada do que simplesmente conhecer ou contemplar a sua essência; ainda que se chegue a mais depurada expressão filosófica da consciência ou subjetividade, como acontece, de um modo singular, no idealismo alemão.

\section{REFLEXÃO FINAL: SOBRE O SENTIDO DA LIBERDADE HUMANA}

A dualidade da vontade (ut natura / ut ratio) e a doutrina de Tomás sobre a liberdade, assim como o problema da possibilidade de certa "eleição" do fim último em particular (já considerado por Báñez no século XVI e repensado no final do século XX pelos tomistas, como Fabro e Giannatiempo, me levam a uma reflexão sobre o sentido da liberdade em relação à doutrina agostiniana e tomista sobre o amor. Ao considerar essa questão agora, quero somente apontar ou esboçar uma interessante linha de reflexão e investigação: no fundo, qual é o sentido da liberdade pessoal? Há alguma relação entre liberdade e amor? 
Como a vontade está nativamente orientada para o bonum in communi (o bem em geral, o bem do todo e de todos), e, por outro lado, amar é querer o bem para alguém e buscá-lo ativamente, é claro que deve haver uma relação estreita e fundamental entre liberdade e amor.

Não se trata agora da "liberdade de" (a liberdade como indeterminação e independência), senão da "liberdade para". Se o amor aperfeiçoa a vontade - segundo Agostinho e Tomás -, então o cultivo do amor poderia melhorar de algum modo a qualidade da liberdade ou dispor a vontade para exercê-la de acordo com esse profundo desejo ou aspiração da pessoa humana. Nesse sentido, poderia se falar de uma teleologia própria da liberdade em referência ao amor, e até mesmo de uma certa "vocação ao amor" de todo homem: "O amor é o objetivo final e mais elevado ao qual o homem pode aspirar" (FRANKL, 2004, p. 65, tradução nossa). 8 É óbvio que essa vocação tem relação, essencialmente, com o caráter social ou comunitário do ser humano, descrito por Aristóteles, e com a sua inclinação ao estabelecer relações ou criar vínculos com outras pessoas, que tem sido muito destacada pelos pensadores da corrente personalista.

Por definição, a liberdade pode ser exercida em qualquer direção, mas, se é exercida em direções contrárias a essa vocação - contrária ao amor autêntico (cuja dinâmica impulsa à autodoação do amante ao amado) -, a pessoa não está realizando suas melhores possibilidades e pode, casualmente, correr o risco de frustrar a sua vida. À luz dessa reflexão, àquela pergunta de Lenin: "liberdade, para quê?", caberia responder: "liberdade para amar". Na verdade, há uma orientação interna da liberdade para a plenitude humana. Desapegada de sua finalidade própria, que é a que leva a realizar o amor verdadeiro, a liberdade pode ficar desorientada ou reduzida à mera capacidade de escolher coisas segundo um arbitrio pessoal, à margem da verdade e do bem do homem.

Tabela - Léxico relativo ao desejo e à vontade: Aristóteles e Tomás de Aquino.

\begin{tabular}{ccc}
\hline Aristóteles & Tomás de Aquino & Irwin $^{9}$ \\
\hline órexis & appetitus (inclinatio) & desire \\
\hline boúlesis & voluntas & wish (rational desire) \\
\hline thymós & irascibilis appetitus & spirit \\
\hline epithymía & Concupiscibilis appetitus & appetite (concupiscentia) \\
\hline
\end{tabular}

Fonte: Elaborada pelo autor.

8 - "El amor es la meta última y más alta a la que puede aspirar el hombre."

9 - Cf. Irwin (1992, p. 453-473). 


\section{Will and freedom in Thomas Aquinas}

Abstract: Thomas Aquinas, in Italian Tommaso d'Aquino (1225-1274), is a Christian author of the medieval period who, with extraordinary intellectual boldness and breadth of vision, methodically and critically dialogues with Aristotle as well as with the entire philosophical and theological tradition, elaborating a balanced and original synthesis - as beautiful as it is difficult - about the great philosophical problems. This paper aims at the concepts of will and freedom. Here will is considered a potency or faculty (superior) of human soul: the rational appetite, the appetite for the good and for happiness. Thomas Aquinas is the recipient and interpreter of a rich collection of reflections and theses on will. On the one hand, Aristotle offers Thomas Aquinas the philosophical framework and basic conceptual apparatus, enriched by the Stoics as well as Alexander of Aphrodisia. And on the other hand, the horizon of Christian thought, well articulated in patristic with Greek philosophy, provides him a new and more specific perspective on will, offering the keys to understanding the anthropological and ethical relevance of it, and its peculiar relationship with understanding and the other potencies of human soul. Therefore, the concept of will in Thomas Aquinas, whom overrides will over intellect, acquires his fundamental elements in Aristotle, Augustine, Maximus, and Damascene.

Keywords: Freedom. Will. Happiness. Thomas Aquinas. Free will.

\section{REFERÊNCIAS}

FRANKL, V. E. El hombre en busca de sentido. Ed. rev. e atualiz. Barcelona: Herder, 2004.

IRWIN, T. H. Who discovered the will? In: TOMBERLIN, J. E. (ed.). Philosophical perspectives. 6. Ethics. Northridge: California State University, 1992. p. 453-474.

POLO, L. La voluntad y sus actos (I). Pamplona: Servicio de Publicaciones de la Universidad de Navarra 1998. (Cuadernos de Anuario filosófico, serie universitaria, n. 50).

SANTO TOMÁS DE AQUINO. Suma de teología. Edición dirigida por los Regentes de Estudios de las Provincias Dominicanas en España. Madrid: Biblioteca de Autores Cristianos (BAC), 1988.

Recebido em julho de 2018. Aprovado em outubro de 2018. 